Revista de Economia Política, vol. 31, no 2 (122), pp. 262-282 abril-junho/2011

\title{
A psicologia econômica como resposta ao individualismo metodológico
}

\author{
RUTH HOFMANN \\ VICTOR PELAEZ*
}

This paper aims at presenting and discussing some of behavioral models developed by Economic Psychology which is considered an irrelevant field of research for many economists yet. On highlighting the multidisciplinary convergence notably from economists' interests by psychology, it is done emphasis to the discussion of the role played by methodological individualism in the psychological reduction of the homo economicus. Such a reduction has, on the one hand, made harder the conciliation between the individual and the collective level of analysis. On the other hand, it made closer economists and psychologists in the common interest of developing methods capable of understanding the economic behavior under a perspective which allows the integration of the complexity of collective dimension in which the individual makes part.

Keywords: economic psychology; methodological individualism; rationality; Katona's model; Strümpel's model; Van Raaij's model.

JEL Classification: B5; B59.

\section{INTRODUÇÃO}

No esforço de desenvolvimento e consolidação de suas teorias, a Ciência Econômica (CE) recorre a instrumentos e métodos tidos como capazes de garantir seu alcance explanatório e sua funcionalidade. As diferentes vertentes teóricas visam à legitimação de seus modelos, o que justifica suas incursões a diferentes áreas do conhecimento, seja à história, à física, à biologia, à matemática, à sociologia ou à

\footnotetext{
* Respectivamente, do Departamento de Engenharia de Produção, Universidade Federal do Paraná. E-mail: ruthofmann@gmail.com, e professor associado do Departamento de Economia da Universidade Federal do Paraná. E-mail: victormpelaez@gmail.com. Submetido: Fevereiro 2008; Aprovado: Novembro 2009.
} 
estatística. Certamente alguns métodos e alguns ramos do saber, em função de fatores historicamente determinantes, foram mais privilegiados que outros na construção de teorias econômicas, seja na condição de parâmetro de credibilidade científica, seja na condição de referencial para analogias.

Os pressupostos comportamentais adotados na teoria econômica - sobretudo na abordagem neoclássica — refletem uma "psicologia econômica" fundamentalmente reducionista porque orientada por postulados de versões exacerbadas do individualismo metodológico (IM). A racionalidade é exemplo da fragilidade empírica dos princípios sobre os quais se alicerça a teoria microeconômica tradicional. Assumindo que o comportamento do indivíduo e da firma - enquanto unidades isomorfas de análise - é norteado por uma racionalidade maximizadora, a microeconomia neoclássica abre espaço a discussões que não se limitam à esfera do econômico.

A preocupação com a previsão e com a mensuração dos fenômenos econômi$\cos$ fez dos métodos quantitativos protagonistas do discurso econômico predominantemente formalista, ficando relegadas à obscuridade acadêmica outras práticas teóricas e metodológicas que primam pela consistência empírica. É esse o caso da Psicologia, cujo caráter instrumental jamais desfrutou do mesmo status epistemológico conquistado pelo arcabouço matemático na Economia, ainda que muitas das variáveis modeladas sejam comportamentais. Tampouco tem sido devidamente reconhecido o fato de ser da própria essência da ciência econômica a compreensão da psicologia humana.

A literatura econômica está repleta de variáveis sociológicas, institucionais e psicológicas. $\mathrm{O}$ interesse próprio, as expectativas, a racionalidade, as propensões marginais a consumir, poupar e investir, o comportamento de manada, a alienação, o fetichismo da mercadoria, a maximização da utilidade e o "satisfazimento" são alguns dos termos que reportam à psicologia do controverso homo economicus. Não obstante, a Psicologia Econômica (PE) é ainda um campo relativamente incipiente de investigação para muitos economistas. Para outros, é uma disciplina consolidada, uma "ciência autônoma", com definições e métodos próprios. Tal ideia se contrapõe a uma perspectiva heterodoxa que enfatiza a importância da interdisciplinaridade.

Psicologia Econômica é uma expressão que designa, evidentemente, a convergência sinérgica entre Psicologia e Economia. O presente artigo tem por objetivo discutir o potencial de convergência dessas disciplinas, a partir da apresentação e da discussão dos modelos comportamentais propostos por Strümpel (1976), Katona (1975) e Van Raaij (1981) na tentativa de aprofundar o entendimento do perfil psicológico do homem econômico (HE). Ao longo da discussão, dá-se ênfase ao papel do IM na redução psicológica do HE, tendência essa que, por um lado, tem dificultado a conciliação entre um nível individual e um nível coletivo de análise e, por outro, tem promovido a aproximação de economistas e psicólogos imbuídos do desenvolvimento de métodos e abordagens capazes de apreender o comportamento econômico em sua riqueza e complexidade.

As últimas décadas têm sido marcadas por um esforço crescente de fundamen- 
tação empírica da teoria econômica em suas diferentes linhas de pesquisa. O próprio Journal of Economic Psychology (JEP), núcleo da difusão acadêmica das discussões, tem contado com uma quantidade substancial de contribuições de artigos de cunho experimental e empírico. Além disso, muitos trabalhos têm discutido a relação entre Psicologia e Economia. Ainda que inegavelmente relevantes, não podem ser analisados a fundo nos limites deste trabalho. Optamos pelo aprofundamento no artigo de Van Raaij (1981) por ser o trabalho de encetamento do JEL, o qual pode ser considerado como um marco histórico para o desenvolvimento da PE. Além de ser a expressão de uma tentativa de construção de um modelo psicológico destinado à análise e explicação do comportamento econômico, é uma síntese introdutória que dá o tom da "gênese formal" de um espaço para a publicação de trabalhos que visam à associação sinérgica entre psicologia e economia.

$\mathrm{O}$ artigo estrutura-se em cinco seções, além desta introdução. A primeira seção trata do IM na teoria econômica e do reducionismo psicológico ao qual o HE é submetido. A segunda seção busca uma definição de "Psicologia econômica". Seguindo-se a essa caracterização da disciplina, serão destacadas as principais contribuições da interação entre CE e Psicologia (novas concepções de HE), sobretudo no que reporta à relação entre um nível individual e um nível coletivo de análise.

\section{O INDIVIDUALISMO METODOLÓGICO NA TEORIA ECONÔMICA}

A emergência e a consolidação de uma disciplina autônoma do saber fazem necessária a delimitação de seu objeto de análise e o desenvolvimento de métodos apropriados de investigação. A peculiaridade do objeto de cada disciplina requer uma abordagem crítica da adequação dos métodos à investigação do objeto, uma vez que a adequação do objeto ao método, em detrimento da adequação do método ao objeto, tem implicações teóricas importantes e quase nunca profícuas. Esse cuidado é necessário para que o teórico não seja surpreendido quando seu objeto de investigação "teima em não ser aprisionado pelos ditames da lógica formal" (Ganem, 1996, p. 120). Adotando o homo economicus como objeto de análise, a Ciência Econômica (CE) restringe suas investigações ao comportamento estritamente econômico dos agentes. Como a concepção de HE está fundamentalmente associada ao conceito de racionalidade, a redução da unidade de análise da CE ao comportamento racional dos agentes assume uma trajetória eminentemente axiomática.

$\mathrm{Na}$ medida em que a explicação do aspecto econômico do comportamento humano requer algum tipo de modelo ou de "esquema da conduta humana", a emergência da CE vem acompanhada da definição de uma "psicologia econômica" rudimentar do HE, psicologia que não pode ser tomada na acepção científica do termo, uma vez que fundamentada no senso comum e em constatações empíricas de um contexto histórico específico. Impregnada dos pressupostos morais e filosóficos da sociedade europeia do início do século XVIII, a concepção de homem (e não apenas de $\mathrm{HE}$ ) que inspira aos autores clássicos às primeiras construções teóricas está originalmente associada ao conceito de racionalidade. Oscilando entre 
descritivo e normativo, o conceito de racionalidade transforma o HE em unidade básica de análise, dado que a racionalidade utilitarista e egoísta do HE, inspirada na racionalidade kantiana, "o indivíduo como sujeito único, único criador e fim último da racionalidade de seus atos" é hipótese indispensável para construção de uma teoria de equilíbrio nos moldes clássicos (Miguens, 1958, pp. 15-16).

A necessidade de se adotar ou de se construir modelos de comportamento econômico, de se adotar ou de se construir uma "psicologia econômica", acompanha a necessidade de uma discussão metodológica da CE na medida em que essa psicologia assume uma trajetória axiomática. Reynaud (1967, p. 8) ressalta que "como era indispensável adotar na Economia algum esquema da conduta humana, certos economistas criaram-no à revelia dos trabalhos dos psicólogos. Escolheram, dessa maneira, os produtos de sua própria imaginação." Nos termos de Boland (1990, p. 24): "The behavioral hypothesis upon which we build our economic theories are, so to speak, representations of our ignorance". Os postulados comportamentais são assim tomados como axiomas, numa acepção muito particular de conduta e natureza humana, em geral, e econômica, em particular.

O IM, definido por Udehn (2002, p. 497) como "a principle, rule or program telling historians and social scientists how to define collective concepts, explain social phenomena, and/or reduce macro to micro" tem caráter metodológico normativo, definindo a trajetória metodológica que melhor se adapta ao aperfeiçoamento do conhecimento científico nas ciências sociais. O IM, enquanto critério normativo de cientificidade, tem como contrapartida, na CE, a difusão da ideia de que o micro-reducionismo é a única abordagem válida. Esse micro-reducionismo requer que níveis superiores sejam explicados em termos de níveis inferiores de análise (Young e Philp, 2002). Como consequência da tentativa de adequação metodológica, tem-se um esforço de promover a microfundamentação da teoria econômica. É esse o caso do marxismo analítico ${ }^{1}$, por exemplo. Mas trata-se de um movimento maior: em detrimento de quaisquer referências a determinantes supra -individuais, prevalecem, na CE, uma postura atomicista e o esforço de redução dos níveis agregados ao nível individual de explicação (Soromenho, 2000). Esse movimento faz parte do que Possas (1997) define como "a cheia do mainstream".

A microfundamentação é uma exigência de coerência dos participantes de determinada matriz teórica, sobretudo da neoclássica. Nesse sentido, quando esses teóricos compartilham do mesmo objeto de estudo, micro e macroeconomia diferem somente com relação à especificidade de seus propósitos e com relação a questões de agregação (Soromenho, 2000). Para Ganem (1996, p. 113), a busca de microfundamentos da macroeconomia neoclássica tem por objetivo identificar

\footnotetext{
${ }^{1}$ A tentativa de prover microfundamentos às explicações econômicas não é exclusividade da teoria neoclássica, sendo passível de identificação inclusive entre os novos-keynesianos. O IM metodológico é uma das estratégias de microfundamentação, sendo que, no caso da TEG, assume uma trajetória axiomática e reducionista. Em termos gerais, a microfundamentação é uma alternativa às abordagens extremas do holismo, as quais acabam por abstrair por completo o comportamento individual como fator determinante dos fenômenos coletivos.
} 
“[...]as leis de conjunto que reflitam comportamentos maximizadores individuais. Por sua importância epistemológica, essa frente de pesquisa acabou se impondo para os neoclássicos como o único empreendimento rigoroso”. A ideia de que uma abordagem científica está necessariamente baseada em algum tipo de individualismo deve ser questionada, o que é particularmente importante quando se trata de um tipo de IM que supõe um reducionismo axiomático diretamente vinculado à utilização de modelos de atores racionais.

Udehn (2002) distingue os IMs segundo diferentes graus de intensidade, entre versões fortes e fracas. No extremo dos IMs fortes estariam aqueles de tendência atomicista, dentre os quais estão: o IM da teoria do contrato social, que tem como ponto de partida um indivíduo associal desvinculado de instituições; e o IM da teoria do equilíbrio geral (TEG), que tem como ponto de partida um indivíduo isolado, sem relações sociais. Nessa classificação, à medida que os IMs passam a incorporar instituições ou elementos de explicação de caráter coletivo, dirigindo-se a abordagens mais holísticas, deixam de ser IMs fortes e passam a ser classificados como IMs fracos.

Em escala descendente de intensidade, ao IM da TEG seguir-se-ia o IM da escola austríaca, menos extremo por assumir o indivíduo como ser social ou cultural que atribui significado subjetivo às suas próprias ações e aos artefatos humanos. O IM popperiano, no mesmo sentido, reconhece a pertinência das instituições, seja como variáveis exógenas nos modelos sociais, seja como antecedentes das explicações sociais científicas: no primeiro caso, as instituições podem ser explicadas em termos de indivíduos, e, no segundo, podem explicar as ações individuais (Udehn, 2002).

A versão mais fraca de IM incorpora, com maior frequência, elementos estruturalistas de análise. Trata-se do extremo oposto ao IM atomicista, o IM de Coleman, permeado de noções estruturalistas. Este IM admite totalidades sociais compostas de posições inter-relacionadas, sendo estas totalidades estruturas cuja existência independe dos indivíduos particulares que ocupam as diferentes posições (Udehn, 2002).

A partir das distinções entre os diferentes graus de intensidade dos IMs, Udehn (2002) esboça algumas definições distintivas entre os IMs: individualismo natural, para os IMs da teoria do contrato social e da TEG; individualismo social, para o IM da escola austríaca; individualismo institucional, para o IM de Adam Smith, e principalmente para o IM popperiano e, finalmente, individualismo estrutural, para o IM de Coleman. Esta última versão, uma "síntese" de elementos individualistas e holísticos, seria predominante entre os sociólogos e marxistas heterodoxos individualistas metodológicos.

$\mathrm{Na} \mathrm{CE}$, dos clássicos aos neoclássicos, o IM assume grau ascendente de intensidade. Na economia clássica o IM associado à teoria do contrato social vincula-se à noção de ordem espontânea, entendida também como ordem natural ${ }^{2}$ (D. Hume, A. Ferguson e A. Smith), e é considerado por Udehn (2002) um tipo de individua-

\footnotetext{
${ }^{2}$ Essa "ordem natural" deve ser entendida no sentido de que, "no que tange à sua atividade material, os indivíduos relacionam-se enquanto possuidores de mercadorias e as relações econômicas assumem
} 
lismo institucional (por incorporar elementos institucionais de explicação), assumindo em John Stuart Mill, mais do que em Smith, o matiz mais extremo.

In A System of Logic (1843), Mill argued that all social sciences are based on laws of mind, or human nature. It is possible to find empirical laws, or generalizations, describing large-scale social phenomena, but a causal explanation of these empirical laws requires psychological laws. Because of this, Mill is generally considered to be a psychological reducionist and a methodological individualist. In order to distinguish Mill's methodological individualism from other versions of this doctrine, it is sometimes called "psychologistic individualism". (Agassi ${ }^{3}$, apud Udehn, 2002, p. 482).

Ainda que dentre os autores clássicos o IM já se faça presente, são os autores neoclássicos que lhe atribuem particular importância. É com a Revolução Marginalista do final do século XIX que a CE definitivamente passa a ser uma ciência individualista (individualistic science), na qual as explicações dos fenômenos econômicos são formuladas a partir da avaliação subjetiva dos seres humanos. Da Escola Austríaca à TEG, passando-se pelo utilitarismo inglês de Jevons ${ }^{5}$, o IM é predominante. Mas é no contexto da abordagem neoclássica que a TEG apresenta um IM particular, extremamente reducionista e atomístico, ao tomar como ponto de partida o indivíduo isolado, sem relações sociais, o qual interage em um mercado com tecnologia e instituições dadas (Udehn, 2002). Nessa abordagem, a realidade, em sendo passível de divisão em unidades independentes, poderia ser compreendida ignorando-se as relações entre elas (Usunier, 1997).

a forma de trocas. Os atos dos indivíduos resultam, então, numa série de consequências que não são desígnios da vontade humana" (Soromenho, 2000, p. 192).

${ }^{3}$ Agassi, J. Methodological individualism. British Journal of Sociology, vol. 11, pp. 244-270, 1960.

${ }^{4}$ Lembrando que a subjetividade desempenha um papel importante aos teóricos dessa escola. Para Menger (1983, p. 304): “[...] o valor é algo subjetivo, não somente no que tange a sua natureza como no tocante à medida de determinação do mesmo. Sempre e em toda parte os bens têm 'valor' para [grifo do autor] certos indivíduos, em relação a determinados indivíduos, e somente para tais indivíduos têm valor determinado [grifo do autor]".

${ }^{5}$ Para Jevons (1983, p. 34-35): “[...] a mente de um indivíduo é a balança que faz suas próprias comparações, e é o juiz final das quantidades de sentimentos. Mas, numa mente, um impulso é comparado apenas em relação a outros impulsos na mesma mente, nunca em relação a impulsos em outras mentes [...] Em consequência, a comparação dos impulsos deve estar sempre confinada ao âmago do indivíduo. Devo destacar aqui que, apesar de a teoria supor a investigação da condição de uma mente e basear nessa investigação toda a Economia, na prática é um conjunto de indivíduos que será tratado. As formas gerais das leis da Economia são as mesmas no caso de indivíduos e nações; e, na realidade, é uma lei operando no caso de um grande número de indivíduos que dá origem ao conjunto, representado nas transações de uma nação. Praticamente, no entanto, é impossível detectar a operação de leis gerais desse tipo nas ações de um ou de uns poucos indivíduos [...] Admitindo-se que temos um número suficiente de casos independentes podemos então detectar o efeito de qualquer tendência [grifo do autor], por mais débil que seja". 
O extremado IM da TEG 6 toma forma com Walras. Segundo Prado (1994), como a teoria pura elaborada por Walras busca fundamentações seguras, a estrutura lógica do modelo de equilíbrio geral deriva de axiomas. Supõe-se que os indivíduos entram em cena (no mercado) prontos à tomada de decisão: "O que é importante notar é que eles são pensados aí como seres que têm um conhecimento claro e distinto, completo e inequívoco, das próprias preferências assim como das técnicas de produção disponíveis. Só concebidos desse modo podem se tornar axiomas; só assim pode ser encontrado um fundamento seguro para o exercício dedutivo" (Prado, 1994, p. 8).

A concepção walrasiana de ciência econômica pura ${ }^{7}$, ou "[...] a natural science of things, where isolated individuals respond to impersonal prices", conforme descreve Udehn (2002, p. 482), fundamenta-se em um individualismo mais radical do que o individualismo da escola austríaca, e mesmo do que o utilitarismo inglês, representado principalmente por Jevons ${ }^{8}$.

It is obvious that GET [General Equilibrium Theory] represents a radical form of methodological individualism, where the actions of individuals are seen as resulting from $(a)$ her/his psychology, $(b)$ the physical surrounding, and $(c)$ the actions of other individuals. According to Lawrence Boland ${ }^{9}$ (1982, 13ff.), not only GET but also neoclassical economics as a whole, is a manifestation of psychologistic individualism. The rule guiding this form of methodological individualism says that no economic explanation is considered sucessful until all exogenous variables have been reduced to psychological states of individuals and natural constrains. Social institutions may appear in the models of neoclassical economics, but only as endogenous variables. (Udehn, 2002, p. 499)

No IM da teoria neoclássica, os indivíduos são reduzidos a "peças de uma máquina” (Prado, 1994, p. 12), ou "invólucros sem conteúdo, simples instrumentos da prevalência das regras de racionalidade atribuídas à concorrência” (Possas 1990, p. 12). O reducionismo da teoria neoclássica passa a ser um "sistemismo mecânico" na demonstração lógico-matemática da superioridade do mercado (Ga-

\footnotetext{
${ }^{6}$ Embora a TEG não ignore as relações entre as unidades interdependentes que toma em análise, assume como dados, independentemente dessas relações, pressupostos referentes às decisões individuais de produção e consumo. Nesse sentido, assume uma postura axiomática no que reporta aos postulados psicológicos tão importantes à compreensão e explicação da conduta humana em sua dimensão econômica.

${ }^{7}$ Nas palavras de Walras (1983, p. 3), sua obra pode ser definida como um "curso elementar de Economia Pura Racional”.

${ }^{8}$ Jevons (1983, p. 37) define sua obra como "a mecânica da utilidade e do interesse individual".

${ }^{9}$ Boland, L. W. The foundations of economic method. London: Allen \& Unwin, 1982.
} 
nem, 1996), na explicação de "[...] como de ações individuais independentes resulta, não intencionalmente, um estado social coerente" (Prado, 1994, p. 12).

A perspectiva reducionista concebida a partir do IM e inerente ao HE leva a uma separação e a uma oposição entre o indivíduo e o seu meio socioinstitucional, uma oposição entre o individual e o coletivo, o primeiro enquanto parte e o último enquanto todo. Partindo da ação individual, a explicação de uma ordem (ou equilíbrio) social fundamenta-se na motivação egoísta dos agentes ${ }^{10}$. Eventuais desvios são compensados, e, no agregado, desaparecem. Pressupostos unitários e ações individuais, na distinção que contrapõe o individual e o coletivo, constituem problema teórico e metodológico na medida em que, uma vez separados, tenta-se alcançar o todo pela transcendência das partes, reduzindo-se as "leis" sociais a "leis" psicológicas. A teoria psicológica implícita nessa abordagem do comportamento econômico dos agentes tem por objetivo adequar-se à análise do comportamento de um indivíduo em particular: o indivíduo “atomístico" que habita o universo teórico clássico e neoclássico requer uma psicologia específica, uma psicologia que parte de suposições como o egoísmo, a racionalidade e a maximização da utilidade. A base psicológica da teoria econômica não deve, como salienta Granger (1955, p. 169), ser entendida em seu sentido científico tradicional, dado que: "Do psicológico ao econômico existe uma diferença estrutural essencial, diferença que se impõe pouco a pouco no pensamento econômico através de um certo número de tentativas para 'axiomatizar uma psicologia econômica', e assim definir 'uma microestrutura subjacente aos macrofenômenos"”.

É partindo de postulados assumidos como válidos, a exemplo da racionalidade, que se promove a redução psicológica axiomática do HE. Nota-se, diante disso, que dentre os aspectos relevantes para a análise crítica da teoria neoclássica está a redução da unidade de análise da CE (o HE) ao comportamento estritamente econômico dos agentes. Se do ponto de vista metodológico essa teoria apresenta-se coerente, a sua consistência torna-se questionável na medida em que o comportamento do indivíduo é considerado ex-ante e desvinculado de seu ambiente socioinstitucional.

\footnotetext{
${ }^{10}$ Trata-se de uma leitura reducionista de obra de Smith. Para este, o mercado seria responsável pela emergência da ordem não apenas econômica, mas também social, cabendo, segundo Ganem (2000), duas interpretações do conceito: o mercado como operador técnico ou mecanismo de alocação ótima (numa leitura simplista e reducionista difundida entre os neoclássicos) e o mercado como ordem social. Esta última abordagem mostra-se muito mais abrangente: “[...] o mercado é entendido como algo mais complexo do que um lócus de troca e a mão invisível como mais do que um simples mecanismo de ajuste automático, representando a própria viabilização da ordem social, seu operador último, sua forma de organização social” (Ganem, 2000, p. 11). A leitura canonizada pelos neoclássicos, ao contrário, reduz a mão invisível a um operador técnico capaz de compatibilizar, automaticamente, oferta e demanda, e toma o interesse privado e o self-interest por equivalentes, resultando disso que “[...] o indivíduo seria caracteristicamente autocentrado, isolado, autosuficiente, fechado em si mesmo e poderia perfeitamente ser traduzido pela noção de homem econômico racional da tradição neoclássica." (Ganem, 2000, p. 25).
} 


\section{ESBOÇANDO UMA DEFINIÇÃO DE “PSICOLOGIA ECONÔMICA”}

Os critérios e concepções de ciência e cientificidade prevalecentes na teoria econômica historicamente aproximaram-na mais de abordagens formalistas e matematizantes do que de quaisquer outras. De forma análoga a outras disciplinas, a CE tomou parte no "projeto histórico de racionalidade", cujo ápice foi (e talvez ainda seja) a tentativa de matematização do mundo (Lima, 2000), alvo de incisivas críticas metodológicas ${ }^{11}$. Atribuindo a matematização e o atual fracasso explanatório da CE à tentativa de aproximação da disciplina com modelos físicos, mecanicistas e atomísticos, Hodgson (1995) propõe a utilização de metáforas e analogias com o universo biológico, em detrimento da aproximação com abordagens matematizantes e formalistas. Para o autor, a inovação teórica seria facilitada pela transferência abdutiva ${ }^{12}$. Nesse sentido, parte importante da "jornada heterodoxa" de redefinição da trajetória de desenvolvimento da CE é norteada pela busca, em outras áreas do conhecimento, de fundamentos mais consistentes para a disciplina.

A psicologia, assim como a CE, é uma ciência composta de linhas de pensamento orientadas por diferentes posições teóricas e metodológicas. Também visando ao status científico, essa disciplina esforça-se por delimitar seu objeto, tomando-o à luz de abordagens mecanicistas, atomicistas, funcionalistas, estruturalistas ou fenomenológicas, cada qual com seus méritos e limites (Figueiredo, 2003). As áreas de investigação desse campo incluem, por exemplo, neuropsicologia, psicologia aplicada, psicologia comportamental, psicologia experimental, psicologia organizacional, psicologia cognitiva e psicologia social ${ }^{13}$. Essa diversidade, quando em interação com a diversidade de abordagens econômicas, pode ter como resultado tanto o desenvolvimento da CE - por uma via heterodoxa - quanto o enrijecimento de um IM reducionista. Desnecessário, portanto, advertir que a aproximação entre psicologia e CE deve ser criteriosa.

\footnotetext{
${ }^{11}$ Goergescu-Roegen (1980) chega mesmo a afirmar que grande parte do que tem sido feito em economia tem se resumido a exercícios vazios com símbolos, à "aritmomania", sendo a descrição da realidade através de conceitos "aritmomórficos" insuficiente à compreensão do mundo econômico.

12 “A ideia abdutiva nos chega como um relâmpago. É um ato de perspicácia sumamente falível. É certo que os distintos elementos da hipótese já estavam em nossa mente, mas é a ideia de unir o que já havíamos pensado que se pudesse unir o que ilumina a nova ideia ante nossa contemplação" [tradução livre] (Hodgson, 1995, p. 41).

13 “A Psicologia Social ocupa-se dos efeitos do ambiente social e cultural sobre o comportamento e a experiência individuais. Ora, algumas pessoas poderão argumentar que esse é, de fato, o objeto de estudo de toda a Psicologia e, recentemente, aumentou o número dos que compartilham do ponto de vista de que toda a Psicologia é Psicologia Social. Contudo, se considerarmos a história das investigações sobre percepção, memória, pensamento e desenvolvimento humano, concluiremos haver muitos psicólogos que não aceitam esse ponto de vista. Eles examinaram processos básicos como se ocorressem fundamentalmente do mesmo modo em todos os homens e em todos os tempos; esse pressuposto simplificador criou amiúde um útil quadro de referência para o exame dos processos cognitivos básicos e proporcionou uma considerável soma de compreensão. Mas como o homem não ocupa um vazio sociocultural, existem limites ao conhecimento que pode ser obtido, embora ele finja que os obtém" (Gahagan, 1976, p. 19-20)
} 
Nas últimas duas décadas o interesse pela relação entre psicologia e economia aparece nos trabalhos de Earl (1990), Lewin (1996), Rabin (1998) e Kahneman (2003). No Brasil, em particular, Ferreira (2007) apresenta a proposta de um modelo psicanalítico para tomada de decisões econômicas, bem como um riquíssimo resgate histórico da PE. Oriundos de outras áreas, em especial a Educação, trabalhos empíricos sobre o desenvolvimento psicológico (ou psicogênse) de conceitos econômicos também têm sido publicados. Embora não se autoenquadrem na PE, despertam seu interesse.

Entre tantas obras, não há consenso quanto ao que vem a ser PE. Embora haja semelhanças em aspectos essenciais, algumas definições soam antagônicas. Por essa razão, serão aqui apresentadas algumas das definições esboçadas, basicamente, por autores que publicaram artigos relacionados no Journal of Economic Psychology. Longe de buscar uma definição absoluta, a intenção aqui é apresentar algumas das perspectivas de economistas e psicólogos que pretendem uma integração entre esses ramos distintos do saber, sejam instigados pelas deficiências metodológicas decorrentes do IM e do reducionismo axiomático do HE, sejam provocados pelo intrigante aspecto econômico do comportamento humano.

Reynaud (1967, p. 9-10) define a PE como "o estudo da economia abordada em seu aspecto 'subjetivo' ou 'mental' [...] A Psicologia Econômica trata das questões subjetivas colocadas pela disposição das riquezas, utilizando os conceitos e métodos da Psicologia e da Economia, dos quais realiza a síntese e, se necessário, provoca a superação pela descoberta de noções e métodos originais”. É nesse sentido que o autor ressalta o caráter "autônomo dessa nova ciência". Calcada no IM inerente à abordagem neoclássica, essa concepção de PE encontra no indivíduo a unidade básica de investigação: "O estudo dos próprios fenômenos coletivos pode, com frequência, efetuar-se no nível do indivíduo. Cada indivíduo é, de certa maneira, um espelho de todos os fenômenos humanos, e o que diz respeito ao grupo em si deve encontrar-se de alguma forma quando se observa cada um dos sujeitos; de outro modo, como é que se poderia atingir o social?” (Reynaud, 1967, p. 15).

Partindo da crítica à racionalidade onisciente dos agentes econômicos, a PE tem encontrado no comportamento do consumidor um vasto campo de investigação. Nesse sentido, Albanese (1987, p. 5) estabelece, como vínculo metodológico entre CE e psicologia, a relação entre preferências e personalidade. A crítica do autor refere-se às preferências, consideradas dadas, na teoria ortodoxa. Ao tentar explicar as variações na natureza das preferências do consumidor a partir dos diferentes níveis de desenvolvimento da personalidade, o autor argumenta que a natureza humana reflete-se na natureza das preferências. Nesta abordagem, as relações interpessoais passam a ser fundamentais: "Through the internalization of interpersonal relationships, the socially determined status-role bundles that are ultimately reflected in the consumers' scale of preferences. Therefore, a theory of the internalization of interpersonal relations in the personality represents an integrative framework and a common ground of analysis which embraces the variety of factors considered in the disciplines of economic and psychology".

$\mathrm{Na}$ definição proposta por Van Raaij (1981, p. 2), quando da apresentação do 
primeiro volume do Journal of Economic Psychology, tem-se que: "Economic psychology is concerned with the study of economic behavior". Por comportamento econômico o autor define "[...] the behavior of consumers/citizens that involves economic decisions, and the determinants and consequences of economic decisions". Trata-se de decisões econômicas em sentido amplo: "Economic decisions involve money, time, and effort to obtain products, services, work, leisure, the choice between product alternatives, spending $v s$ saving decisions. In fact, all decisions that involve a choice or a trade-off of some alternatives or an investment that will bring future profits or benefits may be called an economic decision". Mais especificamente: "Economic decisions are characterized by sacrifices to be made by the actor, an evaluation of present or future benefits of one's expenditure (spending $v s$ saving), an evaluation of the expected benefits of some alternatives, and a relatively concrete variable of behavior. A customary criterion for an economic decision is the monetary, temporal, or effort sacrifice, for expected present or future well-being of oneself" (Van Raaij, 1981, p. 2).

Nessa perspectiva, os determinantes das decisões econômicas envolvem fatores pessoais (personalidade, estilo cognitivo ${ }^{14}$, estilo de vida, normas e valores sociais que estimulam ou inibem certos comportamentos); fatores religiosos e culturais; fatores situacionais (renda disponível, tamanho da família, tipo de casa e situação do mercado) além de fatores econômicos em geral (percepção da distribuição de renda, taxa de inflação e de juros, nível de desemprego e política econômica do governo). Os fatores econômicos em geral levam, segundo o autor, a atitudes e expectativas otimistas ou pessimistas que influenciam as decisões de investimento e poupança dos agentes. Neste sentido, as consequências das decisões econômicas são a satisfação e o bem-estar decorrentes do consumo (Van Raaij, 1981).

A PE, para Van Raaij, é simultaneamente parte da Psicologia e da Economia. É parte da psicologia porque emprega princípios psicológicos de comportamento e métodos psicológicos de mensuração, a exemplo de entrevistas e pesquisas de laboratório. Em oposição a Lassare (apud Roland-Lévy, 1997), Van Raaij afirma que a PE não é um tipo específico de psicologia aplicada, embora aplique técnicas e teorias psicológicas, enfatizando: "Economic psychology is developed by studing economic behavior" (Van Raaij, 1981, p. 6). As áreas da psicologia de maior importância à PE seriam a psicologia experimental, a psicologia cognitiva e a psicologia social. Por outro lado, a PE é parte da economia no sentido de que novas variáveis contribuem, argumenta, para uma melhor explicação e predição dos fenômenos econômicos. Cabe destacar os interesses do autor, enquanto cientista econômico, na exploração de técnicas e conceitos de psicologia: "Additional psychological variables may increase the explained variance in a multiple regression equation. Economic psychology, then, plays a servant's role in an economic model. A better integration of psychological variables in economic science will be reached, when both economic

\footnotetext{
${ }^{14}$ A expressão "estilo cognitivo" foi cunhada por Allport (1937) para designar abordagens individuais de resolução de problemas, de recebimento e recuperação de informações memorizadas.
} 
and psychological variables are entered into a model, into hypothesis, and theories." (Van Raaij, 1981, p. 6). Essa colocação, bastante infeliz, está em contraste evidente com os autores que defendem ser a PE uma ciência diferente.

Pela definição de Roland-Lévy (1997, p. 575), tem-se que: "Economic psychology is a specific branch of psychology - a branch of applied psychology using methods, and techniques borrowed from social psychology". Nessa concepção, a $\mathrm{PE}$ assume a conotação pragmática subjacente à psicologia aplicada, razão pela qual necessariamente deve ser funcional.

Para Spash e Biel (2002, p. 551), a Psicologia Social é um dos ramos da psicologia que pode ser particularmente válido para promover a interdisciplinaridade capaz de romper com algumas das principais limitações da teoria econômica ortodoxa, a exemplo da suposição de que a irracionalidade e a ignorância parcial são anômalas e podem, portanto, ser ignoradas, assim como o podem os vários aspectos da psicologia humana, como o altruísmo, os hábitos, normas e valores sociais, a ética, as crenças etc.

Nessa mesma linha, em Psychologie Sociale et Économie, Lassare (1995) tenta introduzir na Economia o estudo da Psicologia Social, seu ponto de partida. O autor apresenta a Psicologia Social através de exemplos e problemas econômicos, tratando de necessidade, satisfação, motivação, percepção, representações e escolhas: "Centred on specific dimensions of the economic world, Lassare shows how one can, with a new look and new approaches, define new objects such as economic socialization, and new scientific discipline known as economic psychology" (Roland-Lévy, 1997, p. 576).

A partir das contribuições da psicologia tem-se evoluído nas discussões sobre o perfil psicológico do HE, a ser discutido na próxima seção. Indo além desse perfil, a Psicologia social contextualiza e dá consistência coletiva (como ciência social) aos postulados comportamentais do homo economicus, provê subsídios à superação da dicotomia entre micro e macro na teoria econômica.

\section{O NOVO PERFIL PSICOLÓGICO DO HOMEM ECONÔMICO}

Das incursões de economistas à Psicologia têm resultado novos modelos teóricos de comportamento econômico dos agentes. Esses modelos caracterizam-se pelo reconhecimento de suas limitações cognitivas/perceptivas e pela inclusão de fatores pessoais na determinação do comportamento. Para Thaler (2000), trata-se de uma tendência da CE que será consolidada no futuro (próximo) da disciplina. Nessa trajetória de redefinição dos modelos de comportamento econômico, a CE passará da análise do homo economicus à análise do Homo sapiens, o HE perderá QI e tornar-se-á um slow learner. No quadro delineado por Thaler (2000), as espécies que habitam os modelos econômicos tornar-se-ão heterogêneas, os economistas passarão a estudar a cognição humana e farão a distinção entre teorias normativas e descritivas. De fato, são tendências identificáveis nos modelos desenvolvidos recentemente. 
À luz da PE como disciplina que se ocupa do comportamento econômico dos agentes, Van Raaij (1981) faz uma análise de dois modelos de comportamento econômico, o de Katona (1975) e o de Strümpel (1976), e, em seguida, propõe seu próprio modelo. Os três modelos são descritos a seguir.

O modelo de Katona (1975) é relativamente simples: supõe que variáveis psicológicas intervêm entre o estímulo econômico, i.e., as variações no ambiente econômico, e a resposta comportamental, como esquematizado na Figura 1:

Figura 1: Modelo de Katona

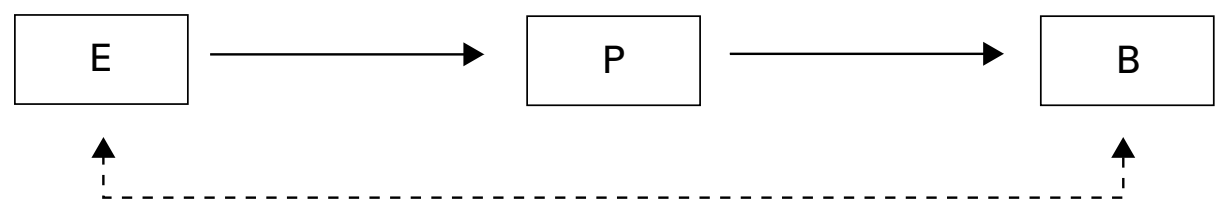

Fonte: Van Raaij (1981).

E são as condições econômicas (economic conditions) que envolvem, por exemplo, recessão, nível de desemprego, taxas de juros e de inflação, obrigações contratuais, padrão de vida, taxa de impostos etc. As condições econômicas que E representa são, no modelo, as condições e oportunidades econômicas objetivas para o indivíduo ou para um pequeno grupo. As expectativas e aspirações ou seu estilo de vida constituem exemplos das características pessoais, $P$, na figura. A variável $P$ é interveniente no processo, atua como um filtro na determinação do comportamento $B$ (behavior) do consumidor ou empresário individual. $\mathrm{O}$ comportamento $B$ inclui decisões de poupança e investimento, disposição, compra e utilização de bens e serviços. Ao nível agregado, e ressalta-se que não há maiores detalhes no modelo referentes ao tratamento metodológico deste, o comportamento de empresários e consumidores influenciaria o desempenho (sucesso e flutuações) do sistema econômico, havendo assim um efeito de feedback de $B$ (comportamento) para $E$ (condições econômicas). Deve-se destacar, segundo Van Raaij (1981), que no modelo de Katona (1975) o estímulo econômico não influencia as características pessoais, e sim as condições econômicas $E$, sendo que as características pessoais $P$ são as variáveis que influenciam o comportamento $B$.

O modelo de Strümpel (1976) é um pouco mais sofisticado que o modelo proposto por Katona (1975). As variáveis incluídas no modelo de Strümpel (1976) são o bem-estar subjetivo ( $S W$ - subjective well-being); o comportamento econômico (B - economic behavior); o descontentamento social (SD - societal discontent); o ambiente econômico (E - economic environment) e as características pessoais $(P-$ personal characteristics $)$. A causalidade do modelo pode ser ilustrada pela Figura 2: 
Figura 2: Modelo de Strümpel

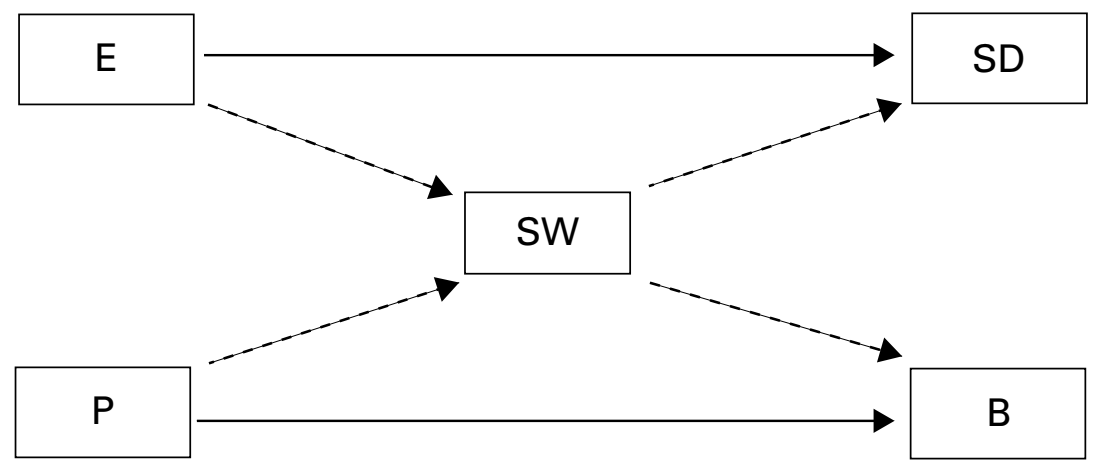

Fonte: Van Raaij (1981).

Os conceitos de ambiente econômico e características pessoais são semelhantes aos utilizados por Katona (1975). O bem-estar subjetivo $S W$ envolve satisfação com trabalho, com consumo, com o casamento, o padrão de vida e o senso de oportunidade. O modelo supõe dois resultados possíveis: o descontentamento social SD (insatisfação com o sistema político, com a política governamental, com o emprego ou com os preços) e o comportamento econômico $B$ (escolha profissional, poupança, gastos investimento, trade-offs entre lazer e trabalho). O ambiente econômico, as características pessoais e o bem-estar subjetivo são responsáveis pelo comportamento econômico, pela satisfação ou insatisfação e pelas atitudes diante de problemas sociais (Van Raaij, 1981).

A principal crítica que Van Raaij (1981) aponta ao modelo de Strümpel (1976) é o fato de que o descontentamento social depende não apenas do bem-estar subjetivo, depende também do comportamento econômico $B$. Além disso, Van Raaij argumenta que as relações entre ambiente econômico e descontentamento social são artificiais ou inexistentes desconsiderando-se as características pessoais $P$ ou o bem-estar subjetivo $S W$ como variáveis intervenientes. A última crítica que o autor aponta ao modelo é a ausência de um efeito de feedback entre o descontentamento social SD e o comportamento econômico $B$, o ambiente econômico $E$ e as características pessoais $P$. O descontentamento social e o comportamento econômico a nível agregado tenderiam a influenciar significativamente as expectativas, aspirações e percepções da realidade econômica, de maneira que o descontentamento social e o comportamento econômico afetam o desempenho do sistema econômico.

Tendo em vista essas deficiências, o modelo proposto por Van Raaij (1981) é mais complexo. Segundo o modelo de Van Raaij, o comportamento econômico é determinado pelo ambiente tal como este é percebido pelo indivíduo, e tem como consequência o bem-estar individual subjetivo. Os resultados do comportamento econômico e do bem-estar subjetivo realimentam o ambiente econômico percebido e o ambiente econômico objetivo. O modelo é ilustrado na Figura 3. 


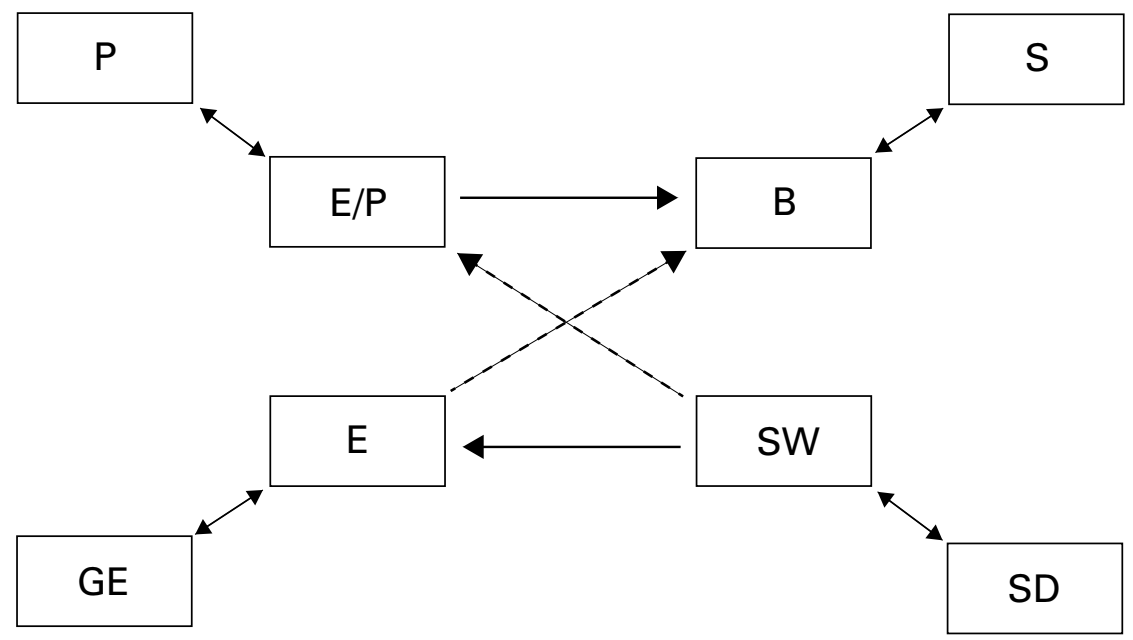

Fonte: Van Raaij (1981).

O ambiente econômico $E$ inclui finanças pessoais, fonte de renda, tipo de emprego e condições de mercado. É influenciado, dentre outros, pela política econômica, por recessões, guerras, condições ecológicas, pela violência estrutural, ou seja, fatores que constituem o ambiente geral GE (general environment). As condições de mercado, o clima de negócios, as expectativas de evolução dos preços, a percepção de posição em grupos de referência, a percepção de distribuição de renda e a percepção de oportunidades constituem a variável E/P (environment as perceived), o ambiente econômico tal como percebido por empresários e consumidores. Desse modo, o comportamento econômico é influenciado não tanto pelo ambiente econômico $E$, mas pelo ambiente econômico percebido. A relação entre é ambos é uma relação de experiência pessoal, social e de comunicação em massa, pois o ambiente econômico objetivo é "experimentado" por empresários e consumidores apenas parcialmente. $\mathrm{O}$ ambiente percebido, $E / P$, por sua vez, é influenciado pelas habilidades de processamento de informação, pela idade, educação, profissão, família, estilo cognitivo, aspirações, expectativas, valores e objetivos, ou, em outros termos, pelos fatores pessoais $P$, e influencia o comportamento $B$. O comportamento $B$ é também influenciado por situações imprevistas $(S)$, como acidentes, casamento, doenças etc. O bem-estar subjetivo $S W$ inclui a satisfação ou insatisfação com a compra ${ }^{15}$, e pode ser definido como a diferença entre os benefícios atuais e os benefícios esperados das decisões econômicas, ou como a diferença entre o desempenho atual e o esperado de um produto ou serviço. O bem-estar subjetivo $S W$ afeta e é afetado pelo descontentamento social, assim como tem impacto no ambiente econômico $E$ e nas condições econômicas percebidas $E / P$. O

${ }^{15} \mathrm{O}$ foco de análise do autor é o consumidor. 
descontentamento social (social discontent,- SD) teria o mesmo sentido que no modelo de Stümpel (Van Raaij, 1981).

A aplicabilidade do modelo, abrangeria, além do comportamento do consumidor, o comportamento econômico organizacional, pesquisas de mercado e a adoção de inovações. Ao tratar do comportamento econômico organizacional, Van Raaij (1987, p. 13) afirma que: "Compared with consumer economic behavior, organizational economic behavior is a relatively unknown area of economic psychology, although there is a vast amount of research and knowledge". Dentre os trabalhos de "Psicologia Econômica Organizacional" a que o autor faz menção está o de Simon ${ }^{16}$ (1970). Van Raaij refere-se ao trabalho deste como uma abordagem do comportamento do produtor a partir da PE, cuja maior contribuição seria a adoção do critério de satisfazimento em detrimento do critério de maximização de lucro. Ainda que reconheça o trabalho de Simon (1970), Van Raaij argumenta que seu modelo, tal como anteriormente descrito, é aplicado também ao comportamento organizacional:

The economic environment $E$ is the environment of the firm or the environment of the department, division or profit center within the firm, including the type and size of the organization. Organizational climate and style, the role of purchasing within the firm, lateral and vertical involvement, perceptions of one's own role and position within the organization belong to the group of $E / P$ variables. The $P$ correlates pertain to the factors already mentionated and choice criteria, learning, loyalty, and risk perception. The situational correlates $S$ are failures of delivery, strikes, legal-political considerations, and governmental protections measures. Organizational economic behavior $B$ includes the decision to make, buy or lease products or components, the choice of facilities, suppliers, distribution channel, the commercialization of new products types, and entering a new market. (Van Raaij, 1981, p. 14)

Neste sentido a psicologia organizacional seria parte da PE na medida em trabalhadores, diretores e empresários tomam decisões sobre a carreira, promoções e horas extras. Trata-se apenas de ajustar os elementos pertinentes no modelo, passando $E$ a representar a organização formal, $P$ as motivações, aspirações, objetivos e personalidades dos empregados, $B$ o comportamento destes, $S$ as oportunidades e $S W$ a satisfação pelo trabalho e o bem-estar dos trabalhadores (Van Raaij, 1981).

Para o autor, a cooperação e a interação entre a psicologia organizacional e a PE tendem a ser particularmente sinérgicas porque, em geral, a PE não se ocupa da investigação da motivação e da satisfação dos membros da firma. Mantendo vínculos com outras disciplinas, embora relacionada, a PE não poderia ser confundida com as pesquisas de marketing, uma vez que este estuda as reações de consumidores ao mix

\footnotetext{
${ }^{16}$ Surpreende a negligência e a superficialidade com que Van Raaij (1981) apresenta o trabalho de Simon (1970). Mesmo que seu objetivo tenha sido apresentar um novo modelo a partir dos precedentes, simplistas e antiquados mesmo para a ocasião, caberia um tratamento mais aprofundado.
} 
de variáveis de marketing, da perspectiva do produtor, enquanto a PE ocupa-se dos efeitos do ambiente econômico sobre as decisões econômicas, principalmente as que se referem a gastos e poupança. Mais especificamente: "Economic psychology is an autonomous science, directed toward the antecedents and consequences of economic behavior, and the antecedents and consequences of economic behavior, and the processes and mechanism underlying economic decisions" (Van Raaij, 1981, p. 16).

A adoção de inovações, para Van Raaij (1981, p. 17), também é passível de explicação através do modelo. Para isso seria necessário admitir que o ambiente econômico não é estritamente econômico, inclui normas e valores referentes à mudança, inovação e modernização, assim como inclui a rede de comunicação entre pessoas e as fontes de comunicação em massa. $\mathrm{O}$ ambiente percebido, diante disso, inclui as características percebidas da inovação, tais como vantagens relativas, complexidade e compatibilidade. Além do ambiente percebido, fatores como ousadia, dogmatismo e cosmopolitismo, a posição na rede de comunicação e o risco percebido da inovação são também importantes. O comportamento $B$ seria a adoção ou não da inovação, estando sujeito a influências situacionais, como a impossibilidade financeira. O bem-estar subjetivo do inovador dependeria da vantagem relativa da inovação sobre os produtos ou processos existentes, da aprovação por parte dos outros, da inovação e da confirmação das expectativas a ela relacionadas. A legitimação da adoção provém da aprovação dos outros agentes, tidos como relevantes, podendo inclusive ser promovida pelos meios de comunicação em massa. A continuidade da adoção de uma inovação, por sua vez, seria determinada pelos fatores de bem-estar subjetivo.

Nota-se que a generalidade de análise do modelo, pretendida pelo autor, é significativa. Em se tratando de um artigo cujo propósito é apresentação da PE, enquanto "disciplina autônoma", não foram aprofundados aspectos metodológicos. Ao tratar de uma "Psicologia Econômica Organizacional", o autor recorre a Simon (1970), e, a título de conclusão, delineia algumas considerações vagas sobre as dimensões macro e micro do comportamento econômico.

\section{A PSICOLOGIA SOCIAL COMO CAMPO A SER EXPLORADO PELA TEORIA ECONÔMICA}

A ausência de consenso quanto à definição da PE decorre sobretudo da natureza bidimensional de sua composição. Na medida em que Psicologia e CE constituem disciplinas autônomas do saber, diferentes agendas e métodos prevalecem na abordagem dos respectivos objetos de análise. A constituição de uma PE, enquanto disciplina autônoma, esbarra em algumas das divergências teóricas e metodológicas entre as duas disciplinas. Lunt (1996) apresenta uma discussão quanto à natureza das relações entre Psicologia e Economia, articulando críticas à postura e às intenções de incursões de economistas ao universo teórico da Psicologia.

$\mathrm{O}$ autor argumenta que há diferenças significativas entre economistas interessados em psicologia e psicólogos interessados em economia: enquanto os psicólogos estão mais interessados nos aspectos sociais das crenças e do comportamento, os 
economistas estão interessados nos aspectos cognitivos e neuropsicológicos como recurso para elaborar as questões referentes à racionalidade neoclássica. ${ }^{17}$ Lunt (1996) apresenta críticas à apropriação, por parte dos economistas, das ideias psicológicas, e propõe que os psicólogos (econômicos) parem de adotar a agenda dos economistas e comecem a examinar a teoria econômica para abrir novas linhas de colaboração que permitam aplicar seus próprios conceitos de psicologia na CE.

Para Lunt (1996, p. 276), a interdisciplinaridade pode assumir diversas formas: uma disciplina pode definir uma agenda à qual outra disciplina pode oferecer técnicas e conhecimento especializado; duas disciplinas podem definir agendas sobrepostas; várias disciplinas podem trabalhar em uma única agenda (geralmente referente a problemas sociais) ou pode haver disputas entre disciplinas para apropriarem-se da caracterização, teorização e método aplicável a determinado fenômeno. É neste sentido que se dá grande parte das incursões de economistas à psicologia, tendo por objetivo principal a elaboração dos modelos de preferência do consumidor e da racionalidade em condições de incerteza: "Although there are differences in the ways that psychological research is assimilated into economics, the basic model is that of psychologist providing descriptions of cognitive biases or behavioral tendencies with which economists can explain deviations from expected utility models" (Lunt, 1996, pp. 276-277). Mais precisamente: "The point is that the interest of economics in pscyhology is not substantively psychological. They do not locate their work in psychological theory, but rather use selected propositions encoding specific effects as labels for putative psychological process in rational decision making under uncertainty" (Lunt, 1996, p. 280).

Lunt (1996) afirma que existem diferenças entre a Psicologia e a CE que tendem a dificultar sua aproximação: enquanto à psicologia são relevantes as observações e a plausibilidade dos dados do comportamento, a economia neoclássica os considera irrelevantes, em especial os comportamentos anômalos, ou seja, aqueles que divergem das previsões dos modelos teóricos. Se as diferenças teóricas e metodológicas entre a Psicologia (disciplina, em sentido amplo) e a CE são significativas, são ainda maiores quando se trata de Psicologia Social e Economia. Segundo o autor, a Psicologia Social tem elementos, teorias e métodos influenciados pela sociologia; é cética quanto à universalidade e vê com dúvidas as reduções ao nível individual para explicar os fenômenos inter e intragrupos, e, principalmente, os fenômenos sociais, razão pela qual há poucos psicólogos sociais adeptos de modelos explicativos que assumem hipóteses baseadas no indivíduo. A "verdade" na Psicologia Social está constantemente sob revisão e contestação. A Psicologia Social considera os processos da vida social desagregada, localizada e histórica, uma contextualização que impede e exclui modelos como os adotados na teoria neoclássica. Essa Psicologia Social tem sido mantida afastada da CE: "In comparison to the appeal of cognitive heuristics in

\footnotetext{
${ }^{17}$ March e Simon (1972, p. 27), por exemplo, elencam os postulados psicológicos e fundamentam sua análise em termos de aspectos referentes ao sistema nervoso central, sobretudo aspectos cognitivos, perceptivos e de processamento de informações.
} 
decision making and the theory of games, social psychological approaches to economic psychology are having little impact in economics" (Lunt, 1996, p. 276-277).

A utilização de elementos de psicologia cognitiva, em detrimento da Psicologia Social, tende a comprometer a explicação dos fenômenos sociais. O exemplo deste equívoco apontado por Lunt (1996, p. 282) é a extrapolação, na teoria econômica, do indivíduo para o agregado:

I suggest that economists have not understood that there are several problems for social psychologists in the way that they appropriate psychological variables. There is a basic problem in taking variables that explain individual level psychological phenomena and using them to explain social behavior. It is one thing to study only aggregate data, by making idealized assumptions about rationality, but it is quite another to take psychologically real accounts and build a model of an agent with bounded rationality. The choice is between an angel and Frankenstein's monster! (Lunt, 1996, p. 282)

Dirigindo-se expressamente aos psicólogos, Lunt (1996, p. 283) afirma:

We have to understand that psychology has became a resource for the economist, and the motivation for integration is all on the side of psychology, and this is made particularly problematic by the kind of psychology utilized within economic theory. In my view, economists are not ready, prepared or even vaguely interested in changing their core assumptions as a response to psychological work. Indeed, we should realize that if an economist sound interested in our work they are only trying us to see what kind of resource we have to offer. The agenda for their interest will be some debate in economics that we won't have even heard of.

As relações entre Psicologia e CE têm sido prejudicadas pela ausência, por parte dos economistas, de interesse nas questões abordadas pela Psicologia Social: "The imperialistic tendencies of economists and the detachment (often ignorance) of psychologists from economics could result in the comparative neglect of social economic psychology" (Lunt, 1996, p. 284). O autor ressalta ainda que, em prejuízo de uma PE interdisciplinar de fato, o relativo sucesso do esforço da CE que tem incorporado variáveis psicológicas (no sentido de psicologia individual e cognitiva), pode tornar-se a forma dominante de PE, e a oportunidade para a construção de uma Psicologia Econômica Social será perdida.

Esperamos que não.

\section{CONCLUSÃO}

Partindo da discussão epistemológica acerca do papel do IM na redução psicológica do HE, o presente trabalho procurou apresentar alguns dos modelos com- 
portamentais desenvolvidos no âmbito da PE em resposta à fragilidade dos fundamentos psicológicos que tem norteado as construções teóricas da CE. Para tanto, argumentou-se que os pressupostos comportamentais adotados na teoria econômica - sobretudo na abordagem neoclássica - vêm refletindo uma PE fundamentalmente reducionista porque orientada por postulados de versões exacerbadas do IM. Exemplo notório é a racionalidade maximizadora atribuída ao indivíduo e à firma - unidades isomorfas de análise.

A PE emerge, nesse contexto, como um esforço de redefinição do "perfil psicológico" do HE, empreendimento caracterizado sobretudo pelo reconhecimento de suas limitações cognitivas. Tomando os argumentos de Lunt (1996), procurou-se ressaltar as dificuldades a serem superadas na integração sinérgica entre as disciplinas matrizes da PE.

$\mathrm{Na}$ transição do nível individual ao nível coletivo de análise, a PE fundamentada na Psicologia Social procede reconhecendo a interdependência dos indivíduos em relação ao seu meio socioinstitucional, contextualizando o comportamento dos atores em ambientes específicos e focando as relações entre os agentes em detrimento do indivíduo isolado. É no reconhecimento do continuum indivíduo-meio como unidade de análise que a PE, conforme proposta por alguns autores, pode permitir a generalização que alcança as totalidades, respeitando a diversidade inter e intra-individual e ressaltando a importância da criação de mecanismos de coordenação do comportamento coletivo. $\mathrm{Na}$ análise das organizações sociais, dentre as quais a firma, esta disciplina faz uso de um conceito de racionalidade distinto da racionalidade microeconômica neoclássica, assumindo a racionalidade um caráter eminentemente relacional.

Ainda que ambas ciências permaneçam numa perspectiva axiomática de análise - a dimensão racional do HE - a principal contribuição que a PE pode proporcionar à CE é a restituição do caráter social de seu objeto de investigação, seja mediante a consolidação de novos modelos comportamentais, seja mediante o incentivo à reflexão epistemológica do IM.

\section{REFERÊNCIAS BIBLIOGRÁFICAS}

ALLPORT, G. W. (1937) Personality: A Psychological Interpretation. New York: Holt \& Co.

ALBANESE, P. J. (1987) "The nature of preferences: an exploration of the relationships between economics and psychology". Journal of Economic Psychology, 8: 3-18.

BOLAND, L. A. (1990) The Methodology of Economic Building: Methodology after Samuelson. London: Routledge.

EARL, P. (1990) "Economics and psychology: a survey", Economic Journal, 100 (402): 718-755.

FIGUEIREDO, L. C. M. (2003) Matrizes do Pensamento Psicológico. Petrópolis: Ed. 12.

FERREIRA, V. R. de M. (2007) "Psicologia econômica: origens, modelos, propostas". Tese de Doutorado, Programa de Estudos Pós-Graduados em Psicologia Social, Pontifícia Universidade Católica de São Paulo.

GAHAGAN, J. (1976) Comportamento Interpessoal e de Grupo. Rio de Janeiro: Zahar.

GANEM, A. (2000) "Adam Smith e a explicação do mercado como ordem social: uma abordagem histórico-filosófica”, Revista de Economia Contemporânea, 4 (2): 9-36. 
GANEM, A. (1996) "Demonstrar a ordem racional do mercado: reflexões em torno de um projeto impossível”, Revista de Economia Política, 16 (2).

GOERGESCU-ROEGEN, N. (1980) Métodos em Ciência Econômica. Rio de Janeiro: Multiplic.

GRANGER, G-G. (1955) Méthodologie Economique. Paris: Presses Universitaires de France.

HODGSON, G. M. (1995) Economía y Evolución: Revitalizando la Economía. Madrid: Celeste.

JEVONS, S. (1983) "A teoria da economia política”, in Os Economistas. São Paulo: Abril Cultural.

KAHNEMAN, D. (2003) "Maps of bounded rationality: psychology for behavioral economics”, American Economic Review, 93, (5): 1449-1475.

KATONA, G. (1975) Psychological Economics. New York, Elsevier.

LASSARE, D. (1995) Psychologie Sociale et Economie. Paris: Armand Colin.

LEWIN, S. B. (1996) "Economics and psychology: lessons for our own day from the early twentieth century", Journal of Economic Literature, 34: 1293-1323.

LIMA, I. V. (2000) Origens e Pertinência da Matematização da Teoria Econômica. Curitiba: CMDE/ UFPR.

LUNT, P. (1996) "Rethinking the relationship between economics and psychology", Journal of Economic Psychology, 17 (2): 275-287.

MARCH, J. G.; SIMON, H. A. (1972) Tereferoria das Organizações. 2. ed. Rio de Janeiro: Fundação Getúlio Vargas.

MENGER, C. (1983) "Princípios de economia política”, In Os Economistas. São Paulo: Abril Cultural.

MIGUENS, J. E. (1958) Sociología Económica: Los Presupuestos Sociológicos de las Teorías Económicas Modernas. Buenos Aires: Depalma.

PICKERING, J. F. (1981) “A behavioral model of the demand for consumer durables”, Journal of Economic Psychology, n. 1: 59-77.

POSSAS, M. L. (1997) “A cheia do "mainstream": comentários sobre os rumos da ciência econômica”, Revista de Economia Contemporânea, n. 1: 13-36.

POSSAS, M. L. (1990) Estruturas de Mercado em Oligopólio. 2. ed. São Paulo: Hucitec.

PRADO, E. F. S. (1994) "A teoria neoclássica (pura) e a teoria neo-austríaca frente ao legado cartesiano", Análise Econômica, n. 21-22: 5-23.

RABIN, M. (1998) "Psychology and economics", Journal of Economic Literature, 36 (1): 11-46.

REYNAUD, P-L. (1967) Psicologia econômica. São Paulo: Difusão Europeia do Livro.

ROLAND-LÉVY, C. (1997) "Psychologie sociale et économie: D. Lassarre, Armand Colin. Paris, 1995", Journal of Economic Psychology, 18 (5): 575-577.

SIMON, H. A. (1970) Comportamento administrativo: estudo dos processos decisórios nas organizações administrativas. Rio de Janeiro: USAID.

SOROMENHO, J. E. C. (2000) “Microfundamentos e sociabilidade”, Economia, 1 (2): 185-219.

SPASH, C. L.; BIEL, A. (2002) "Social psychology and economics in enviromental research", Journal of Economic Psychology, 23 (5): 551-555.

STRÜMPEL, B. (1976) Economic Means for Human Needs: Social Indicators of Well Being and Discontent. New York: Inst for Social Research.

THALER, R. (2000) "From Homo oeconomicus to Homo sapiens", Journal of Economic Perspectives, 14 (1): 133-141.

UDEHN, L. (2002) “The changing face of methodological individualism”, Annual Review of Sociology, 28: 479-507.

USUNIER, J-C. (1997) “Atomistic versus organic aproaches”, International Studies of Management $\&$ Organization, 26 (4): 90-112.

VAN RAAIJ, W. F. (1981) "Economic psychology", Journal of Economic Psychology, 1 (1): 1-24.

WALRAS, L. (1983) "Compêndio dos elementos de economia política pura”, In Os Economistas. São Paulo: Abril Cultural.

YOUNG, O.; PHILP, B. (2002) "Preferences, reductiuonism, and the microfoundations of analytical marxism”, Cambridge Journal of Economics, 26: 313-329. 